\title{
Efeito de embalagens ativas no escurecimento enzimático de batatas (solanum tuberosum) fatiadas e minimamente processadas
}

\author{
Effect of active packages on enzymatic browning in fresh-cut \\ potatoes (solanum tuberosum)
}

\author{
Mateus da Silva Junqueira ${ }^{1}$; Nilda de Fátima Ferreira Soares ${ }^{2 *}$; \\ Roniele Cardoso Reis ${ }^{3}$; João de Deus Souza Carneiro ${ }^{4}$; \\ Ricardo Teixeira Benicio ${ }^{5}$; Sílvia Rosana Colodeti Yokota ${ }^{6}$
}

\section{Resumo}

A vida moderna tem aumentado a demanda por frutas e hortaliças minimamente processadas, que mantêm características próximas ao "in natura", além da praticidade e conveniência. Foi avaliado o efeito de embalagens ativas na inibição do escurecimento de batatas fatiadas minimamente processadas. Filmes de base celulósica, com 30 micras de espessura, foram incorporados com a mistura ácido ascórbico + ácido cítrico (2, 3 e 5\% de cada), antioxidante metabissulfito de sódio $(0,3 ; 0,5$ e 1,\%) e o controle (sem agente anti-escurecimento). As amostras de batatas envolvidas em filme (sem agente) e sem filme apresentaram aumento de $\mathrm{pH}$ de 5,7 para 6,7 após armazenamento, enquanto batatas envolvidas em filmes com adição de compostos químicos apresentaram diminuição de $\mathrm{pH}$ para 5,5. Os filmes incorporados com as misturas de AC e AA mantiveram a coloração inicial da batata durante o período de estocagem, enquanto que os filmes contendo metabissulfito de sódio apresentaram escurecimento intenso das batatas. Este efeito para os filmes com adição de antioxidantes ocorreu em razão da diminuição do $\mathrm{pH}$, abaixo do ponto ótimo de atividade desta enzima, conseguindo reduzir a atividade relativa da enzima à menos de $50 \%$, considerando o filme com adição de antioxidantes sendo mais efetivo no controle do escurecimento enzimático, agindo na inibição da enzima polifenoloxidase.

Palavras-chave: processamento mínimo, batata, escurecimento enzimático, embalagem

\begin{abstract}
The modern life has increased the demand for fresh-cut fruits and vegetables, which maintain closer characteristics to "in natura", beyond the convenience and be ready-to-use. The effect of active packages in the browning inhibition of fresh-cut potatoes was estimate. 30 micra cellulosic films with ascorbic + citric acid addition (2, 3 e $5 \%$ each one), sodium metabisulphite $(0,3 ; 0,5$ e $1 \%)$ and the control (without anti-browning agent). The control treatment with film (without agent) and without film presented increase on $\mathrm{pH}$ after storage from 5,7 to 6,7 while potatoes with $\mathrm{AA}+\mathrm{AC}$ antioxidants addition demonstrated a little decrease to 5,5. Potatoes treatments with AA + AC antioxidants in the films maintained the initial color by all storage period, while potatoes with sodium metabisulphite in the films exhibited a strong browning. This effect for the films with antioxidants addition happened because the decrease on $\mathrm{pH}$,

\footnotetext{
Professor do Departamento de Engenharia Rural - Universidade Federal do Espírito Santo, mateusjunq@yahoo.com.br

2 Universidade Federal de Viçosa, Departamento de Tecnologia de Alimentos, 36.571-000 Viçosa, MG, Brazil, e-mail: nfsoares@ ufv.br

3 Professora do Departamento de Tecnologia Rural e Animal - Universidade Estadual do Sudoeste da Bahia

4 Professor do Departamento de Ciência dos Alimentos - Universidade Federal de Lavras

5 Engenheiro Agrônomo - Universidade Federal de Viçosa

6 Doutora em Ciência e Tecnologia de Alimentos - Universidade Federal de Viçosa

Autor para correspondência
} 
below the optimum point for enzyme activity, improving to reduce the relative enzyme activity lower to $50 \%$, considering then the film with antioxidants addition being more effective to control the enzymatic browning, acting on polyphenoloxidase inhibition.

Key words: fresh-cut, potato, enzymatic browning, package

\section{Introdução}

A vida moderna, com o seu ritmo acelerado, impõe mudanças no comportamento da população, principalmente, nos hábitos alimentares e nas tendências de consumo, podendo ser comprovado pelo aumento das refeições consumidas fora do ambiente doméstico, de uma maneira geral (ABBOTT, 1999).

A demanda por frutas e hortaliças minimamente processadas vem crescendo no mercado alimentício, tendo em vista o desejo do consumidor por alimentos quemantenham seu frescore características próximas ao in natura, além da praticidade e conveniência de se comprar o alimento pronto para o consumo.

Entretanto, algumas características como coloração e textura podem ser fortemente influenciadas pelas etapas do processamento mínimo e da embalagem utilizada no acondicionamento dos produtos. Segundo Sarantópoulos, Oliveira e Canavesi (2001), é de grande importância o desenvolvimento de embalagens adequadas para este tipo de produto, em razão das injúrias mecânicas sofridas durante o processamento que aceleram o metabolismo do vegetal, aumentando a taxa respiratória, levando, assim, à senescência precoce.

No caso da batata fatiada minimamente processada, o escurecimento enzimático ocorre com intensidade, devido ao aumento da atividade da enzima polifenoloxidase (PPO), principalmente em contato com o oxigênio, sendo necessário o tratamento com compostos químicos.

A isoenzima da PPO encontrada em batatas tem uma faixa ótima de atividade com o $\mathrm{pH}$ na faixa entre 6,6 a 7,2, sendo sua atividade relativa reduzida para menos de $40 \%$ quando o $\mathrm{pH}$ encontra-se abaixo de 6,0 (DUANGMAL; APETEN, 1999).
Esta enzima atua principalmente após a ocorrência de danos mecânicos, cortes ou outros tipos de injúrias à célula. A célula injuriada tem, por sua vez, as paredes e membranas corrompidas, comprometendo a separação física entre as enzimas (localizadas nos plastídeos) e os substratos fenólicos (presentes nos vacúolos), favorecendo, assim, a reação de escurecimento (LEE, 2000; MARSHALL et al., 2000; MARTINEZ; WHITAKER, 1995).

O método mais disseminado pela indústria alimentícia para diminuição do escurecimento é o emprego de agentes sulfitantes, por serem eficazes e pelo amplo espectro de aplicação (LANGDON, 1987). Os sulfitos são agentes multifuncionais, pois previnem o escurecimento enzimático e o não-enzimático, controlam o crescimento de microorganismos, agem como agentes branqueadores, antioxidantes ou redutores e realizam outras funções técnicas. Entretanto, os sulfitos apresentam algumas desvantagens, é corrosivo a equipamentos, pode reagir com alguns nutrientes e ainda prejudicar a textura e produzir sabor desagradável nos alimentos.

Alguns compostos antioxidantes naturais, como ácidos cítrico e ascórbico, têm a capacidade de reduzir as quinonas formadas pela ação das oxidases, desta forma, impedindo a formação dos produtos escurecidos; além de poderem agir como inibidores das enzimas oxidativas, através do abaixamento do pH (CARVALHO; ABREU, 2000; BEZERRA et al., 2002).

Ainda, vários inibidores da PPO têm sido utilizados comercialmente em frutas e hortaliças como ácido benzóico e seus derivados (MARTINEZ; WHITAKER, 1995), misturas de ácido ascórbico, ácido cítrico, pirofosfato e cloreto de cálcio (AHVENAINEN, 1996; DUXBURY, 1988, apud 
SON, MOON; LEE, 2001). Uns dos agentes mais importantes são os agentes redutores, como o ácido ascórbico e seus derivados, e os quelantes como o ácido cítrico.

Combinações desses ácidos têm demonstrado eficiência na prevenção de reações de oxidação (WILEY, 1994, apud LINDLEY, 1998). Langdon (1987), mostrou que combinações de ácido ascórbico e ácido cítrico foram eficientes para prevenir o escurecimento em fatias de batatas. Sapers e Miller (1995), apud Laurila, Kervinen e Ahvenainen (1998), verificaram que cozimento com soluções aquecidas de ácido ascórbico/ácido cítrico melhoraram a vida de prateleira de batatas pré-descascadas, sendo obtida uma vida de prateleira média de duas semanas. Santerre, Cash e Vannorman (1988), apud Jiang e Fu (1998), confirmaram que combinações de ácido ascórbico, ácido eritórbico e ácido cítrico foram eficientes na prevenção do escurecimento em maçãs.

Assim, o presente trabalho teve como objetivos:

A. Desenvolver filmes de base celulósica incorporados com a mistura de ácido ascórbico + ácido cítrico ou metabissulfito de sódio em diferentes concentrações.

B. Avaliar a utilização desses filmes para acondicionamento de batatas fatiadas minimamente processadas, acondicionadas sob vácuo em sacos de Nylon/PE e estocadas sob refrigeração.

\section{Material e métodos}

\section{Preparo dos filmes}

Os filmes foram produzidos pelo sistema "cast "em placas de vidro, pela adição de acetona em polímeros de acetato de celulose (em flocos), formando uma emulsão. Esta emulsão foi então distribuída sobre placas de vidro, com auxílio de um espaçador de 30 micras, para permitir a homogeneidade da espessura do filme. Após a evaporação da acetona e secagem natural o filme pronto foi retirado da superfície da placa de vidro
Para produção dos filmes com agente antiescurecimento foram adicionadas à emulsão de acetato de celulose, antes da distribuição nas placas de vidro, a mistura de ácido ascórbico + ácido cítrico (2, 3 e $5 \%$ de cada), ou o metabissulfito de sódio $(0,3 ; 0,5$ e $1, \%)$. O controle foi o filme de acetato de celulose (sem agente anti-escurecimento).

\section{Preparo da matéria-prima}

A matéria-prima utilizada foi batata Solanum tuberosum, cultivar Asterix, adquirida no comércio local.

As amostras foram processadas em ambiente a $18-20{ }^{\circ} \mathrm{C}$, passando pelas seguintes etapas: seleção de material sadio, uniforme, sem doenças; descascamento, com auxílio de descascador manual de legumes e corte em rodelas, utilizando um processador de alimentos Robot Coupe, com uso de lâmina de $5 \mathrm{~mm}$.

Após cortadas, as rodelas de batata passaram pelo processo de higienização, para redução da possível contaminação microbiana, em tanque com água a aproximadamente $5^{\circ} \mathrm{C}$, com $200 \mathrm{ppm}$ de cloro ativo, específico para frutas e hortaliças, por 10 minutos, seguido por enxágüe em outro tanque com água a $5^{\circ} \mathrm{C}$, com $3 \mathrm{ppm}$ de cloro ativo, para retirada do excesso de cloro absorvido na etapa de higienização.

Feita a higienização, as rodelas foram centrifugadas, em centrífuga doméstica por 30 segundos, com velocidade de $800 \mathrm{~g}$, para retirada do excesso de água incorporada durante a etapa de higienização. Foram então colocadas 5 rodelas por saco de Nylon/Polietileno e separadas pelos diferentes filmes. Batatas sem filme também foram embaladas, colocadas em bandejas. Os sacos foram selados sob vácuo e armazenados sob refrigeração (5 $\pm 1^{\circ} \mathrm{C}$ ) durante 30 dias para realização das análises de cor, $\mathrm{pH}$ e teor de sulfito na batata. Foram embalados 18 sacos por tratamento, sendo três repetições por dia de análise $(0,6,12,18,24$ e 30 dias $)$ para cada tratamento. 
Avaliação da cor das amostras

A leitura da cor foi realizada em colorímetro modelo ColorQuest II (Sphere) ("Hunter Lab Reston", VA), conectado a um computador provido do software Universal.

Para cálculo das coordenadas de cor, foi estabelecido o iluminante D65 (luz do dia 6500K) e o ângulo de $10^{\circ}$ para o observador e a escala do sistema de cor CIE Lab.

As coordenadas medidas foram: $L^{*}$ que representa a luminosidade numa escala de 0 (preto) a 100 (branco); a* que representa uma escala de tonalidades de vermelho $(0+a)$ a verde $(0-a)$ e $b^{*}$ que representa uma escala de tonalidades de amarelo $(0+b)$ a azul (0-b).

As fatias de batata foram colocadas em uma placa de vidro, evitando sobreposições e realizadas as leituras de reflectância diretamente.

\section{Avaliação da migração do sulfito para a batata}

As amostras intercaladas com os filmes contendo metabissulfito de sódio foram submetidas a quantificação de sulfito, segundo metodologia

descrita por Araújo (1999), para verificar a migração de sulfito para as amostras.

\section{Avaliação da variação do ph do meio}

A verificação do $\mathrm{pH}$ das amostras foi realizada em todos os tratamentos, sendo triturada $15,0 \mathrm{~g}$ de amostra em $100 \mathrm{~mL}$ de água e medido o $\mathrm{pH}$ em potenciômetro à temperatura ambiente.

\section{Análise dos dados}

Os valores de leitura do $\mathrm{pH}$ e das concentrações de sulfito foram apresentados descritivamente. Para oss dados coletados da leitura de cor foi realizada análise de regressão no programa estatístico SAS (1995).

O experimento foi realizado em três repetições.

\section{Resultados e discussões}

As rodelas de batata apresentaram $\mathrm{pH}$ inicial variando de 5,5 a 5,9. Todos os tratamentos, exceto $\mathrm{o} \mathrm{AA}+\mathrm{AC} 2 \%$ e $\mathrm{AA}+\mathrm{AC} 5 \%$, aumentaram o $\mathrm{pH}$ atingindo o máximo de 6,5. As amostras de batata sem filme e com filme sem aditivos apresentaram valores de $\mathrm{pH}$ acima de 6,0 .

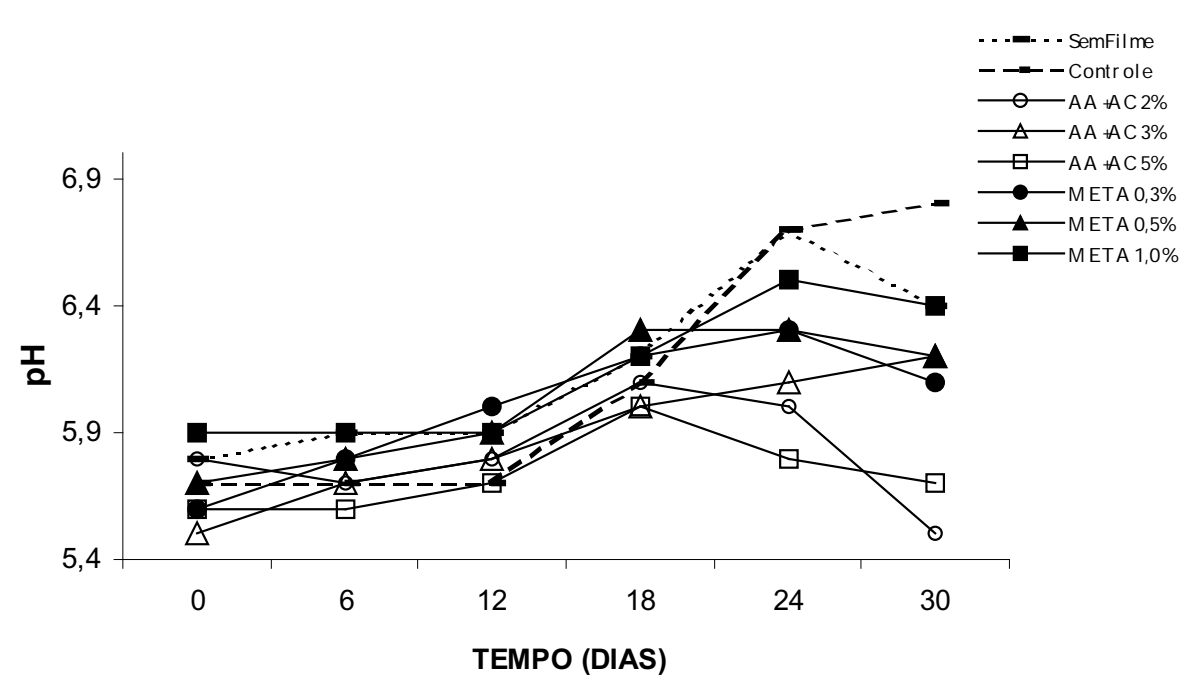

Figura 1. Valores de $\mathrm{pH}$ das amostras de batata minimamente processada em contato com diferentes filmes durante o período de armazenamento sob refrigeração $\left(5 \pm 1^{\circ} \mathrm{C}\right)$. 
Verifica-se que batatas em contato com o filme incorporado com a mistura de ácido cítrico e ácido ascórbico mantiveram a coloração inicial da batata durante o período de estocagem, enquanto que batatas acondicionadas com filme contendo metabissulfito de sódio apresentaram escurecimento intenso (Figura 2).
Aeficiência na manutenção da cor dos tratamentos com os filmes (AC + AA) foi constatada também pela análise visual (Figura 3), entre as batatas armazenadas por 28 dias, quando comparado com o tratamento controle.

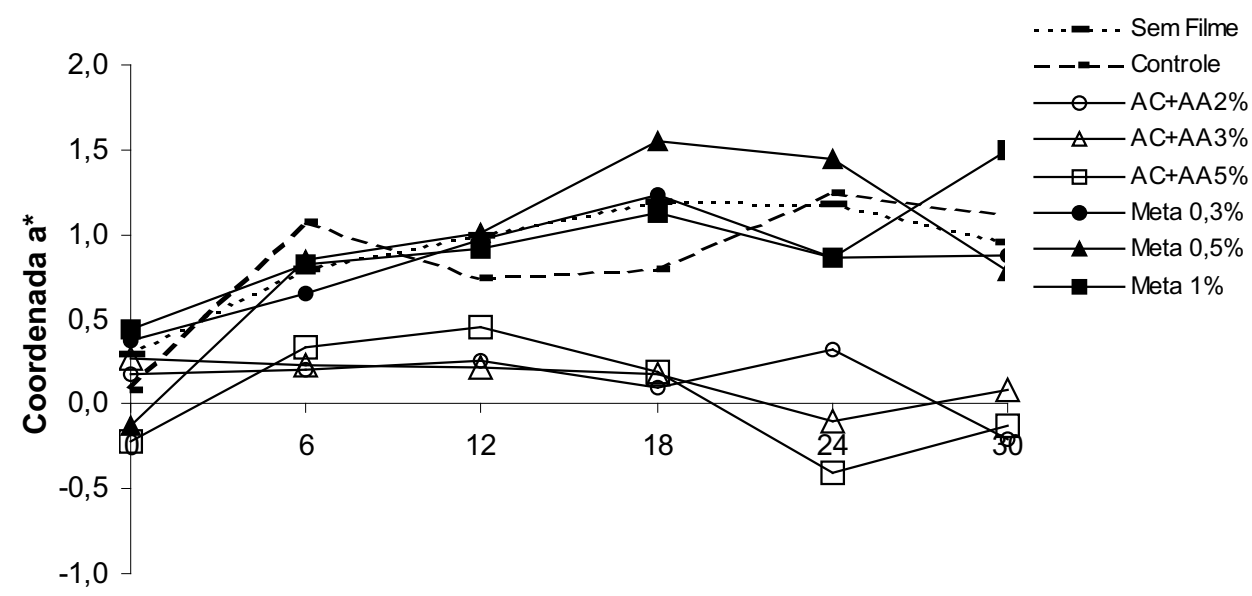

TEMPO (DIAS)

Figura 2. Valores de cor para a coordenada a*, em amostras de batatas minimamente processadas durante o período de armazenamento sob refrigeração.
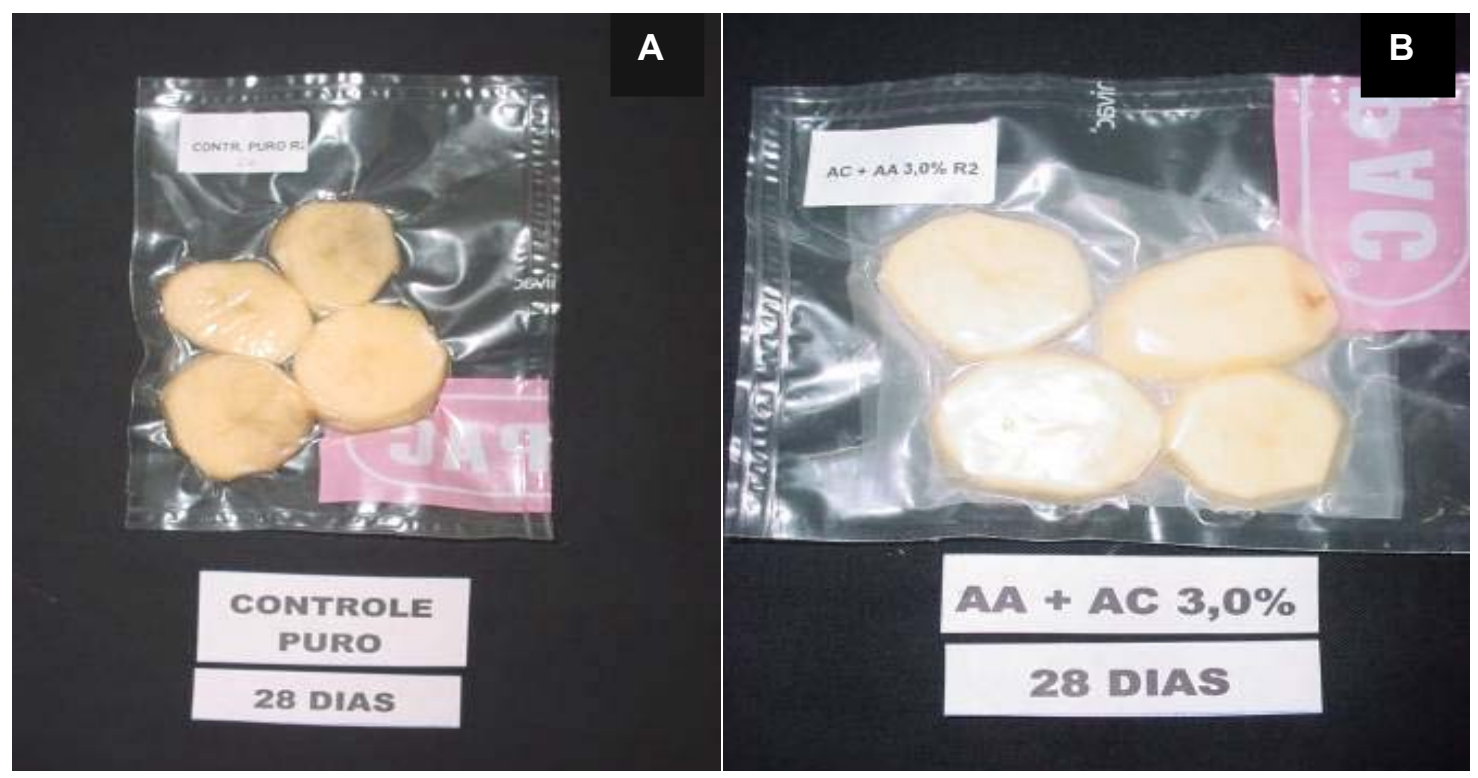

Figura 3. Efeito dos filmes sobre o escurecimento de batatas fatiadas embaladas a vácuo, sendo: A) controle, e B) mistura de ácidos cítrico e ascórbico, a 3\%. 
Parte do efeito observado para os filmes com adição de AA + AC ocorreu em razão da diminuição do $\mathrm{pH}$, menor que 6,0, abaixo do ponto ótimo de atividade desta enzima, reduzindo assim a atividade relativa da enzima à menos de $50 \%$, inibindo o escurecimento excessivo das fatias de batata.

Constatou-se que o metabissulfito não atuou efetivamente na prevenção do escurecimento das batatas minimamente processadas. Na quantificação do sulfito presente nas amostras foi constatado que a migração do sulfito para o produto foi mínima (dados não mostrados), sendo necessário estudo adicional para elaboração de embalagens que proporcionem a atuação do sulfito no armazenamento.

\section{Conclusão}

Conclui-se que a mistura de ácido ascórbico com ácido cítrico foi efetiva no controle do escurecimento enzimático, agindo na inibição da enzima polifenoloxidase.

Portanto esses filmes são de grande potencial para uso no acondicionamento de batatas minimamente processadas estocadas sob refrigeração.

\section{Referências}

ABBOTT, J. A. Quality measurement of fruits and vegetables. Postharvest Biology and Technology, Amsterdam, v. 15, n. 1, p. 207-225, 1999.

AHVENAINEN, R. New approaches in improving the shelf life of minimally processed fruit and vegetables. Trends in Food Science and Technology, Cambridge, v. 7, n. 6, p. 179-187, 1996.

ARAÚJO, J. M. A. Química de Alimentos: teoria e prática. 2. ed. Viçosa: UFV, 1999. 416 p.

BEZERRA, V. S.; PEREIRA, R. G. F. A.; CARVALHO, V. D.; VILELA, E. R. Raízes de mandioca minimamente processadas: efeito do branqueamento na qualidade e na conservação. Ciência Agrotecnica, Lavras, v. 26, n. 3, p. 564-575, 2002.
CARVALHO, V. D.; ABREU, C. M. P. Frutas do Brasil 5: abacaxi pós-colheita transporte e armazenamento. 2000. Disponível em: <http://www.ceinfo.cnpat.embrapa.br/ pdf/poscolheita/5tranarm.pdf $>$. Acesso em: 10 jul. 2003.

DUANGMAL, K.; APENTEN, R. K. O. A comparative study of polyphenoloxidases from taro (Colocasia esculenta) and potato (Solanum tuberosum var. Romano). Food Chemistry, London, v. 64, n. 3, p. 351-359, 1999.

JIANG, Y.; FU, J. Inhibition of polyphenol oxidase and the browning control of litchi fruit by glutathione and citric acid. Food Chemistry, London, v. 62, n. 1, p. 4952, 1998.

LANGDON, T. T. Preventing of browning in fresh preparated potatoes without the use of sulfiting agents. Food Technology, Chicago, v. 41, n. 64, p. 66-67, 1987.

LAURILA, E., KERVINEN, R.; AHVENAINEN, R. The inhibition of enzymatic browning in minimally processed vegetables and fruits. Postharvest News and Information, Oxfordshire, v. 9, n. 4, p. 53-65, 1998.

LEE, C. Y. Enzymatic browning reaction. In: FRANCIS, F. J. Encyclopedia of Food Science and Technology. $2^{\text {th }}$. ed. New York: John Wiley \& Sons, 2000. p. 208-218.

LINDLEY, M. G. The impact of food processing on antioxidants in vegetable oils, fruits and vegetables. Trends in Food Science and Technology, Cambridge, v. 9, n. 8/9, p. 336-340, 1998.

MARSHALL M. R., KIM J, WEI C.I. Enzymatic Browning in Fruits, Vegetables and Seafoods. Nutrition and Food Science Department,Alabama, 2000. Disponível em: http://www.fao.org/ag/Ags/agsi/ENZYME FINAL/ Enzymatic\%20Browning.html

MARTINEZ, M. V.; WHITAKER, J. R. The biochemistry and control of enzimatic browning. Trends in Food Science and Technology, Cambridge, v. 6, n. 6, p. 195200, 1995.

SANTERRE, C. R.; CASH, J. N.; VANNORMAN, D. J. Ascorbic acid/citric acid combinations in the processing of frozen apple slices. Journal of Food Science, Chicago, v. 53 , n. 6 , p. $1713-1716,1988$.

SARANTÓPOULOS, C. I. G. L.; OLIVEIRA, L. M.; CANAVESI, E. Requisitos de conservação de alimentos em embalagens flexíveis. Campinas: CETEA/ITAL, 2001.

SAS. User's guide: basic and statistic. Cary: SAS, 1995.

SON, S. M.; MOON, K. D.; LEE, C. Y. Inhibitory effects of various antibrowning agents on apple slices. Food Chemistry, London, v. 73, n. 1, p. 23-30, 2001. 